\title{
EDITORIAL
}

\section{SERVIÇO DE ENFERMAGEM EM SAÚDE PÚBLICA DO HOSPITAL DE CLÍNICAS DE PORTO ALEGRE: 40 ANOS DE HISTÓRIA}

O Serviço de Enfermagem em Saúde Pública (SESP) do Hospital de Clínicas de Porto Alegre (HCPA) completou 40 anos em 2012 e foi pioneiro na implantação da consulta de enfermagem ambulatorial. O SESP foi organizado considerando a infraestrutura para programar a assistência de enfermagem a partir das políticas vigentes e das necessidades da comunidade ${ }^{(1)}$. Na época, foi um grande desafio, considerando que existiam poucos modelos de cuidado de enfermagem ambulatorial. A proposta, então, era tornar dinâmica a assistência com foco no autocuidado e modificar os padrões tradicionais de enfermagem ambulatorial $^{(1)}$. Assim, o SESP foi organizado na forma de Serviço e não de unidade, exatamente para possibilitar a criação de Programas ${ }^{(1)}$.

É preciso reconhecer a ação de pessoas que ocuparam posições estratégicas e estabeleceram marcos referenciais. A primeira chefe em 1972 foi a professora da Escola de Enfermagem da Universidade Federal do Rio Grande do Sul (EENF/UFRGS) Lea Cecília Muxfeldt que, com empreendedorismo, e em conjunto com a coordenadora Prof ${ }^{a}$ Maria Helena Nery iniciaram as atividades do SESP. Somaram-se a esta construção os enfermeiros: Arlete Spencer Vanzin, na área de Enfermagem na Saúde do Adulto; Baltazar Renosi Lápis, na área de Enfermagem Psiquiátrica; Nilcéa Maria Nery Duarte, na área de Enfermagem Obstétrica; Lourdes Falavigna Boeira e Walderez Spencer Uebel, ambas na área de Enfermagem em Puericultura ${ }^{(2)}$.

Durante as décadas de 70 e 80, os objetivos do SESP foram de participar do planejamento, organização e coordenação dos programas de saúde pública existentes no HCPA, considerando a promoção da saúde por meio do autocuidado direcionado ao paciente e sua família; servir de campo de ensino e de pesquisa para a enfermagem em Saúde Pública. O enfermeiro realizava as atividades assistenciais individuais e grupais, a pacientes e seus familiares; atividades técnico-administrativas de educação permanente; supervisão da equipe de enfermagem; organização, execução e avaliação de programas, além das atividades de ensino e de pesquisa integradas com a equipe multidisciplinar e de docentes da EENF/UFRGS ${ }^{(1,2)}$.

Desde a implantação em 1972, a consulta de enfermagem utiliza as etapas do processo de enfermagem, fundamentada na Teoria das Necessidades Humanas Básicas de Wanda Horta, tendo como foco central as necessidades individualizadas de saúde ${ }^{(1)}$. Cabe salientar que o pioneirismo do SESP no Brasil esteve diretamente relacionado à implantação da consulta de enfermagem como atividade independente do profissional enfermeiro oferecida de forma sistemática e contínua à comunidade ${ }^{(1,2)}$. Esta iniciativa influenciou na regulamentação da Lei do Exercício Profissional de 1986, definindo a consulta de enfermagem como atividade privativa do enfermeiro ${ }^{(3)}$.

Adaptando-se a evolução do Sistema de Saúde, os programas foram ampliados e adaptados, inclusive a configuração do SESP foi modificada ao longo dos anos. Desde janeiro de 2009 encontra-se em vigor a atual configuração do organograma do Grupo de Enfermagem do HCPA, onde o SESP é composto por 15 zonas ambulatoriais e a Unidade Básica de Saúde (UBS). A equipe é composta por enfermeiros, técnicos e auxiliares de enfermagem, mantendo o gerenciamento por professoras da EENF/UFRGS e por enfermeiras chefes de unidade do quadro do $\mathrm{HCPA}^{(4)}$.

Atualmente, o SESP mantém as ações direcionadas para os níveis primário (UBS), secundário e terciário (ambulatório) de atenção à saúde, integrado à referência e contra-referência do Sistema Único 


\section{EDITORIAL}

de Saúde (SUS). As atividades assistenciais são desenvolvidas por meio da consulta de enfermagem, de grupos educativos, de visitas domiciliares e de procedimentos específicos. Os Programas de Saúde são: da Criança, da Mulher, do Adulto e Idoso, da Saúde Mental e da Atenção Básica. O acesso às consultas é de acordo com os princípios do SUS, com encaminhamentos de profissionais da instituição, em consonância com a especificidade de cada programa. A busca para qualificar o cuidado vem ocorrendo, fundamentado no método científico da Sistematização da Assistência de Enfermagem (SAE), tendo como marco teórico para o Diagnóstico de Enfermagem (DE) a taxonomia da NANDA-I ${ }^{(2)}$.

Nos últimos anos o SESP tem sido um importante espaço de desenvolvimento de ensino da graduação, pós-graduação e de pesquisas, com ênfase em intervenções clínicas para pacientes ambulatoriais. Considerando o interesse da equipe de enfermagem deste Serviço e, a partir das inúmeras questões de pesquisa que emergem da prática, foi construído e cadastrado no diretório do CNPq o Grupo de Pesquisa em Enfermagem Ambulatorial e em Atenção Básica - GPEAMAB ${ }^{(4)}$. Os resultados de três estudos serão publicados na Revista Gaúcha de Enfermagem, um no número atual e outros dois nas próximas edições.

O registro sistematizado da história da enfermagem é relevante para compreender o que somos hoje como profissão e como profissionais. Dentro do contexto político e social, a memória coletiva também é constituída pelas ações do cotidiano, possibilitando a construção da identidade profissional. A trajetória do SESP caracteriza-se pela constante busca de se adequar as políticas públicas vigentes e aos objetivos institucionais. A equipe de enfermagem mostra-se ciente e motivada para os processos de mudança que visam dinamizar o fluxo de atendimento ao paciente, mantendo a qualidade da assistência que faz parte desta história há 40 anos.

\section{REFERÊNCIAS}

1 Muxfeldt LCF. Contribuição para o planejamento do serviço de enfermagem em saúde pública no Hospital de Clínicas de Porto Alegre: análise da atenção de enfermagem de Saúde Pública [dissertação]. São Paulo: Faculdade de Saúde Pública, Universidade de São Paulo; 1978.

2 Tasca AM, Santos BRL, Paskulin LMG, Záchia S. Cuidado ambulatorial: consulta de enfermagem e grupos. Rio de Janeiro: EPU; 2006.

3 Brasil. Lei nº 7.498, de 25 de junho de 1986: dispõe sobre a regulamentação do exercício da Enfermagem e dá outras providências. Brasília (DF);1986.

4. Hospital de Clínicas de Porto Alegre. Serviço de Enfermagem em Saúde Pública [Internet]. Porto Alegre: HCPA; [2012] [citado 2012 ago 15]; Disponível em: http://www.hcpa.ufrgs.br/content/view/442/662/ 